Macedonian Pharmaceutical Bulletin, 66 (Suppl 1) 219 - 220 (2020)

Online ISSN $1857-8969$

UDC: $616.894-085.32:[582.282 .4: 620.3$

DOI: 10.33320/maced.pharm.bull.2020.66.03.109

Short communication

\title{
Freeze-drying of nanostructured lipid carriers loaded with Salvia off. extract for Alzheimer's disease treatment
}

\author{
Iskra Karakash*, Jovana Vasileska*, Dushko Shalabalija, Ljubica Mihailova, \\ Marija Glavas Dodov, Renata Slaveska Raicki, Maja Simonoska Crcarevska
}

\begin{abstract}
Institute of Pharmaceutical Technology and Center of pharmaceutical nanotechnology, Faculty of Pharmacy, Ss. Cyril \& Methodius University, Majka Tereza 47, 1000 Skopje, R. N. Macedonia
\end{abstract}

\section{Introduction}

NLC (nanostructured lipid carriers) are matrix type colloidal drug carries composed of a mixture of solid (fat) and liquid (oil) phase. Compared to solid lipid nanoparticles NLCs are characterized by higher drug loading capacity, minimized drug expulsion during storage and improved stability as a final product. Commonly used methods for their preparation are high pressure homogenization, o/w microemulsion, solvent emulsification-evaporation or-diffusion, water-in-oil-in-water double emulsion (w/o/w) as well as high shear homogenization and ultrasonication (Üner, 2006). In all cases they are produced as water dispersion and in order to extend their stability and prolong shelf-life the water should be removed using some of available techniques such as freeze-drying, spray-drying etc.

The aim of this paper was to stabilize previously prepared NLC loaded with freeze-dried methanol extract Salvia off. Extract (FSE) for Alzheimer's disease treatment (Taneska et al., 2018) by freezedrying. Several cryoprotectants in different concentration were used and their influence upon particle size and particle size distribution of prepared NLC-FSE was evaluated.

\section{Materials and methods}

\section{Preparation}

The NLC-FSEs were prepared using the solvent evaporation method. The lipid phase was prepared as follows: FSE $(0.025 \mathrm{~g})$ was dissolved in ethanol 96\% (Alkaloid, Macedonia) (10 g) using ultra sonic bath for $10 \mathrm{~min}$ and subsequently phospholipon $90 \mathrm{H}$ (kindly donated by Phospholipid, Germany) (0.1 g) and oleic acid (Sigma-Aldrich, Germany) (0.065 g) were added. The aqueous phase was composed of $0.045 \mathrm{~g}$ poloxamer 407 (BASF, Germany), $0.3 \mathrm{~g}$ tween 80 (Merck, Germany) and $8.805 \mathrm{~g}$ of distilled water. Lipid phase was dropwise added to aqueous phase under constant magnetic stirring $\left(68{ }^{\circ} \mathrm{C}, 500\right.$ rpm; IKA, Germany). Emulsion was stirred for $\sim 2 \mathrm{~h}$ under previous conditions until complete evaporation of ethanol and formation of NLC dispersion. The dispersion was cooled down to room temperature by magnetic stirring $\left(300 \mathrm{rpm}, 25^{\circ} \mathrm{C}\right.$; IKA, Germany) and left over night on $2-8{ }^{\circ} \mathrm{C}$ for recrystallization of the lipid phase.

Freeze-drying

Volume of $0.5 \mathrm{~mL}$ of certain cryoprotectant solution with adequate concentration was added to NLC-FSE formulation (2 $\mathrm{g}$ ) and gently shaked for 1 min. 16 different samples were prepared using 4

\footnotetext{
* iskra.karakash@gmail.com; * vasileskajovana@gmail.com
} 
cryoprotecatnts (mannitol, sorbitol trehalose and saccharose,) each in four different quantities (total lipids (solid+liquid):cryoprotectant ratio of 1:1, 1:2, 1:4 and 1:6). Samples were frozen at $-20{ }^{\circ} \mathrm{C}$ for $2 \mathrm{~h}$ and then transferred at $-80{ }^{\circ} \mathrm{C}$ for $22 \mathrm{~h}$. Freeze drying was conducted at $-47{ }^{\circ} \mathrm{C} 0.05 \mathrm{mBar}$, for $24 \mathrm{~h}$ (Labconco, USA). For comparison, NLC-FSE without cryoprotectant was freeze-dried at the same conditions.

\section{Particle size and distribution determination}

The freeze-dried samples $(30 \mathrm{mg})$ were reconstituted with $0.9 \% \mathrm{NaCl}(50 \mathrm{~mL})$ under magnetic stirring $\left(15 \mathrm{~min}, 25{ }^{\circ} \mathrm{C}, 300 \mathrm{rpm}\right.$; IKA, Germany). The particle size and particle size distribution were measured by laser diffractometry (Mastersizer 2000, Hydro 2000S, UK) using previously validated method (Taneska et al., 2018). Results are expressed as particle size $\left(\mathrm{D}_{50} \pm \mathrm{SD}\right)$ and distribution (Span \pm SD). $D_{50}$ and Span factor of NLC-FSE particles before freeze-drying were also determined.

\section{Results}

$\mathrm{D}_{50}$ and Span factor value of NLC-FSE before freeze-drying were $149.1 \pm 7.25 \mathrm{~nm}$ and $2.59 \pm 1.3$, and in freeze-dried sample without cryoprotectant they were $490.9 \pm 8.02 \mathrm{~nm}$ and 85.27 \pm 7.93 , accordingly. The higher values for D50 and Span of reconstituted freeze-dried sample could be explained by absence of cryoprotectant thus resulting in the formation of agglomerates, most likely due to disruption of the phospholipid layer on the particle surface during the freeze-drying. When sugar alcohols were used as cryoprotectants the lowest observed values for $D_{50}$ and Span were determined in $1: 2$ ratio $(338.8 \pm 4.55 \mathrm{~nm}$ and $5.27 \pm 0.36)$ for manitol and 1:1 ratio for sorbitol $(157.7 \pm 5.87 \mathrm{~nm}$ and $5.77 \pm 0.78$ ), subsequently. In the case of trehalose and saccharose as cryoprotectants best results were obtained for $1: 2$ ratio with $D_{50}$ of $141.9 \pm 2.23 \mathrm{~nm}$ and Span of $4.14 \pm 0.07$ and $155.6 \pm 1.26 \mathrm{~nm}$ and $4.91 \pm 0.08$, accordingly.

Trehalose and sucrose in the lyophilization process form a glass matrix that represents a physical barrier between particles, reduces diffusion and molecular mobility (Abdelwahed et al., 2006). Results indicated that trehalose is more effective cryoprotectant than saccharose most likely related to the water molecule displacement due to the hydrogen bonding between the phospholipid phosphate groups and the hydroxyl groups of trehalose thus resulting with the complexation between trehalose and phospholipid and favoring the stability of the lamellar structure on the particle surface. On the other hand, sucrose does not interact with phospholipid groups and is unable to replace water molecules from the surface of the nanoparticles as in trehalose. The effect of sucrose on the surface of the nanoparticles is most likely of a colligative nature and the extraction of water molecules from the particle surface occurs by an osmotic route (Crowe et al., 2007).

\section{Conclusion}

NLC-FSE were prepared and freeze-dried using manitol, sorbitol, trehalose and saccharose as stabilizers (cryorptotectants) in different concentrations. NLC-FSE sample freeze-dried with total lipids (solid+liquid): trehalose ratio of $1: 2$ showed best results related to D50 and Span after reconstitution

\section{References}

Abdelwahed, W., Degobert, G., Stainmesse, S., Fessi, H., 2006. Freeze-drying of nanoparticles: formulation, process and storage considerations. Adv. Drug Deliv. Rev. 58(15), 1688-1713.

Crowe, J.H., Tsvetkova, N.M., Oliver, A.E., Leidy, C., Ricker, J., Crowe, L.M., 2007. Stabilization of liposomes by freeze-drying: Lessons from nature, in: Gregoriadis, G. (Eds.), Liposome technology 3rd ed. Volume I: Liposome preparation and related techniques. New York: Informa Healthcare USA, Inc. pp. 261-284.

Taneska, L., Kostovska, M., Markova, E., Cambuleva, Lj., Shalabalija, D., Dodov, M.G., Karanfilova, I.C., Petrushevska, M., Raicki, R.S., Crcarevska. M.S., 2018. Nanostructured lipid carriers loaded with Salvia off. extract for intranasal delivery, 11th World Meeting on Pharmaceutics, Biopharmaceutics and Pharmaceutical Technology, Granada, Spain.

Üner, M., 2006. Preparation, characterization and physico-chemical properties of solid lipid nanoparticles (SLN) and nanostructured lipid carriers (NLC): their benefits as colloidal drug carrier systems. Die pharmazie 61(5), 375-386.

Maced. Pharm. Bull. 66 (Suppl 1) 219 - 220 (2020) 